\title{
Characterization of Macrophage-activating Lactic Acid Bacteria Isolated from Mukeunji
}

\author{
Jae-Hwan Kim, Jingmei Li, Seon-Kyeong Han, Pei Qin, Jushin Kim, Yeseul Park, Shin-Young Lee, \\ Yeun Hong, Wooki Kim, and Hae-Yeong Kim* \\ Institute of Life Sciences \& Resources and Department of Food Sciences \& Biotechnology, Kyung Hee University, Yongin, Gyeonggi 17104, Korea
}

Received September 15, 2015

Revised November 30, 2015

Accepted November 30, 2015

Published online April 30, 2016

${ }^{*}$ Corresponding Author

Tel: +82-31-201-2660

Fax: +82-31-204-8116

E-mail: hykim@khu.ac.kr

pISSN 1226-7708

eISSN 2092-6456

○ KoSFoST and Springer 2016

\begin{abstract}
Lactic acid bacteria (LAB) were reported to comprise the majority of the bacterial population in mukeunji, a long-fermented kimchi. This current study investigated the probiotic abilities of LAB isolated from mukeunji. Forty bacterial strains from mukeunji were identified by SDS-PAGE gel patterns, which were further tested for acid and bile tolerance. An assessment of the immuneboosting effects of these strains in RAW264.7 cells was also carried out by measurement of secreted proinflammatory cytokines. Heat-killed LAB were also tested for their contribution to cytokine production because certain $L A B$ are not durable in the digestive tract. Immune-boosting strains were further characterized by SDS-PAGE of whole-cell protein and $16 \mathrm{~S}$ rRNA gene sequencing, resulting in the identification of Lactobacillus plantarum, L. sakei, Weissella cibaria, and Pediococcus parvulus. These data and the fact that mukeunji is highly consumed in Korea, together, highlight the need of detailed epidemiological and animal feeding studies.
\end{abstract}

Keywords: probiotics, lactic acid bacteria, macrophage, cytokine, mukeunji

\section{Introduction}

In the digestive tract, physical inhibition of the influx of potentially detrimental material in the intestinal barrier, including bacteria, acts as a first line of defense, achieved via tight junction proteins and mucus $(1,2)$. However, some bacteria and their products pass through the mucosal lining into the lamina propria, where a complex of immune-related cell types cooperate for removal of "invaders." Among the immune cells, macrophages play a pivotal role in the host defense system, actively participating in both innate and adaptive immune responses. With respect to innate activation, macrophages "chew up" bacteria (i.e., phagocytosis) and produce inflammatory cytokines, including interferon (IFN)- $\gamma$, tumor necrosis factor (TNF)- $\alpha$, and interleukin (IL)-6, which further recruit other immune cells resulting in inflammation (3). Macrophages are unique in that they also initiate the adaptive immune system by "displaying" bacterial peptides to T/B cells (lymphocytes) through a process known as antigen presentation, resulting in adaptive immune responses $(4,5)$.

Probiotics are formulations of living microorganisms and/or microbial stimulants that exert favorable effects, in part by boosting immune cells. Various strains of lactic acid bacteria (LAB) have been widely used as probiotics. Kimchi, a Korean traditional fermented cabbage, contains various strains of bacteria. Jeong et al. $(6,7)$ reported the observation of diverse bacterial species in kimchi, including Leuconostoc, Lactobacillus, Weissella, Lactococcus, Pseudomonas, Rhizobium, Bacillus, Flavobacterium, and Pantoea, which may be derived from raw materials. However, after 20 days of fermentation, Lactobacilli were reported to dominate the bacterial species (6). Our laboratory recently demonstrated that the diversity of $L A B$ species in commercially available mukeunji, a type of kimchi aged more than 6 months, changes during aging. Specifically, Lactobacillus, Weissella, and Leuconostoc dominate the microbial population of freshly prepared kimchi samples, whereas Pediococcus and Lactobacillus are dominant after aging (8). Of interest, certain $L A B$ species isolated from mukeunji, such as Lactobacillus brevis and L. plantarum, possess probiotic properties (9). Specifically, the aforementioned LAB isolates show increased survival in a simulated gastric fluid environment and adhesion to epithelial cell lines. Antioxidant capacity, as assessed by DPPH scavenging, is also increased by these $L A B$ species, indicating that they may provide various health promoting effects, including an increase inimmune function.

With regard to immune activation by LAB, Neumann et al. (10) demonstrated that oral administration of certain species of Lactobacilli increases the number of Kupffer cells (liver-specific macrophages), leading to subsequent clearance of microbes in mice. Similarly, nasal immunization of mice with $L$. casei also aids in the activation of immune systems, resulting in decreased colonization of pneumococcal bacteria (11). Thus, indicating that pre-exposure to certain LAB may 
cause upregulation of the innate immune system with consequent fortification of host defense.

Therefore, in the present study, the macrophage activation properties of probiotic LAB isolated from commercial mukeunji were examined by assessing the production of pro-inflammatory cytokines TNF- $\alpha$ and IL- 6 following exposure to simulated gastric fluid and bile acids. The species present were also identified through genetic assays.

\section{Materials and Methods}

Isolation and grouping of LAB from mukeunji Commercial mukeunji samples were purchased at the Gwangju World Kimchi Culture Festival in 2012 (Gwangju, Korea). Samples were packed on ice immediately, transferred to a refrigerator at $2^{\circ} \mathrm{C}$ within $6 \mathrm{~h}$, and analyzed within $24 \mathrm{~h}$. The samples were ground and diluted for $L A B$ isolation using the same procedures described by Jung et al. (12) and Hong et al. $(8,13)$. Each strain isolated was given an arbitrary designation using the initial of the brand name and serial numbering. $\mathrm{LAB}$ colonies isolated from the mukeunji samples were stored in a $-80^{\circ} \mathrm{C}$ freezer as glycerol stocks until used. Reference $L A B$ strains were obtained from the Korean Collection for Type Cultures (KCTC; Daejon, Korea), the American Type Culture Collection (ATCC; Manassas, VA, USA), and the UC Davis Department of Viticulture and Enology Culture Collection, housed in the UC Davis Department of Viticulture and Enology, University of California, Davis (Davis, CA, USA).

SDS-PAGE of whole-cell proteins followed by 16S rRNA gene sequencing Isolates and reference $L A B$ strains were cultured, and the cells were harvested and disrupted to extract whole-cell proteins according to previously described protocols (12). Whole-cell protein extracts were denatured, and SDS-PAGE was performed as described by Jung et al. (12) and Yoon et al. (14). The gels were then scanned, and the whole-cell protein patterns were compared to group isolates. The chromosomal DNA of selected isolates from each group was then extracted and the 16S rRNA gene was amplified by the polymerase chain reaction (PCR), as described by Hong et al. (13). The sequences of the purified PCR products were analyzed at Genocell Total Biotechnology (Yongin, Korea) using an automated DNA sequencer (Applied Biosystems, Foster City, CA, USA). Sequences of the 16S rRNA gene were collated with the National Center for Biotechnology Information (NCBI) database (15) using the criterion of a minimum sequence identity of $98 \%$.

Acid tolerance of LAB isolated from mukeunji The acid tolerance of $L A B$ isolates was assessed using a modified method from previous reports $(9,16)$. Briefly, isolated $L A B$ were exposed to simulated gastric fluid (SGF) to determine their acid tolerance. A liquid culture of the isolates was centrifuged at $3,411 \times g$ for $15 \mathrm{~min}$ at $4^{\circ} \mathrm{C}$. The cell pellet was then suspended and adjusted to $10^{8} \mathrm{CFU} / \mathrm{mL}$ in $0.05 \mathrm{M}$ sodium phosphate at $\mathrm{pH}$ 2.0, adjusted with $\mathrm{HCl}$. Following incubation in SGF at $37^{\circ} \mathrm{C}$ for $3 \mathrm{~h}$, the cells were spread on an MRS agar plate and incubated at $37^{\circ} \mathrm{C}$ for $48 \mathrm{~h}$. Cells cultured under neutral $(\mathrm{pH} 7.0)$ conditions served as the control.

Bile acid tolerance of LAB isolated from mukeunji Bacterial cultures incubated in SGF were centrifuged at $3,411 \times \mathrm{g}$ for $15 \mathrm{~min}$ at $4^{\circ} \mathrm{C}$. The cell pellets were then used to inoculate MRS broth containing an equal volume of $0.3 \%(w / v)$ ox-gall (Fluka, Lyon, France) to the volume of the supernatant. After $12 \mathrm{~h}$ of incubation, the optical density (OD) of the culture was assessed as an indicator of bacterial growth. MRS broth without the addition of ox-gall served as the control. The bile tolerance of the isolates was expressed as follows $(9,17)$ :

Bile tolerance $(\%)=($ Increment of OD in MRS with ox-gall/ increment of OD in MRS broth without ox-gall)x100.

Macrophage activation and cytokine quantification RAW 264.7 murine macrophage cells were maintained in RPMI640 (Thermo Fisher Scientific, Waltham, MA, USA) complete medium containing $10 \%$ fetal bovine serum (FBS; Thermo Fisher Scientific). Following harvest, the cells were resuspended at a density of $1 \times 10^{6}$ cells $/ \mathrm{mL}$. Next, $1 \mathrm{~mL}$ aliquots of the cell suspension ( $1 \times 10^{6}$ cells) were added to each well of 12-well culture plates, followed by addition of $10 \mu \mathrm{L}$ of live or heat-killed LAB withan $O D=0.8$ at $600 \mathrm{~nm}$. RPMI complete media and $1 \mu \mathrm{g} / \mathrm{mL}$ LPS served as the negative and positive controls, respectively. Following incubation for $24 \mathrm{~h}$, the supernatant was harvested by centrifuging at $300 \mathrm{xg}$ for $5 \mathrm{~min}$. Aliquots of the supernatants were stored at $-80^{\circ} \mathrm{C}$ until used in cytokine assays.

Cytokine assays by ELISA Macrophage culture supernatants were diluted 1,000 times in sterile phosphate buffered saline (PBS; Sigma, St. Louis, MO, USA). Cellular production of TNF- $\alpha$ and IL- 6 was then determined using commercial ELISA kits (eBioscience, San Diego, CA, USA), following the manufacturer's guidelines. Briefly, a transparent 96-well plate was coated overnight by capture antibody, followed by a series of steps for washing and blocking of the Fc regions. Cell culture supernatants and appropriate controls were then transferred into the plate, followed by incubation at room temperature. After a series of washing steps, detection antibody was applied to the wells andthe plates were incubated at room temperature. After another washing step, secondary antibody with HRP was added. Finally, substrate was added and allowed to react for $20 \mathrm{~min}$ before the reaction was stopped by the addition of $2 \mathrm{~N} \mathrm{H}_{2} \mathrm{SO}_{4}$. The quantity of each cytokine (i.e., TNF- $\alpha$ and IL-6) was assessed at an absorbance of $450 \mathrm{~nm}$ and compared to astandard curve obtained using the standards provided in the kit.

Statistics All data were tested for normality followed by One-way ANOVA with Tukey's post-test using GraphPad Prism version 5.00 for Windows. Differences in data at $p<0.05$ were considered statistically significant. 


\section{Results and Discussion}

Screening of LAB from mukeunji for acid and bile tolerance Forty different strains, as determined by their SDS-PAGE gel patterns, were grouped among 270 colonies isolated from the commercially available mukeunji samples tested in this study. Among the 40 strains, 12 (D7, K2, K6, K17, L2, M2-2, M2-3, M2-10, M3-2, M3-7, O8, and W22) displayed significant survival rates when exposed to simulated gastric fluid consisting of sodium phosphate with $\mathrm{HCl}$ at $\mathrm{pH}$ 2.0 , indicating that these strains have the capability to survive in the acidic conditions of the stomach (Table 1 ). The LAB isolates described above were further tested for their tolerance in bile fluid. For this purpose, ox-gall was used in order to mimic the human bile environment. Following exposure to bile fluid, L2, M2-10,D7, and M2-3 exhibited higher tolerance, as shown by their survival rates (85.0, 83.3, 77.1, and 75.0\%, respectively).

In the current study, the tentative properties of mukeunji as an immune-boosting food were investigated. Because probiotics mainly survive in the digestive tract, $L A B$ isolates of mukeunji were tested for tolerance to acid and bile. The results are comparable to a previous report in which certain strains of LAB isolated from kimchi, including L. casei, L. acidophilus, L. sakei, L. plantarum, and Leuconostoc mesenteroides, were shown to have acid tolerance up to $\mathrm{pH} 2.0$ (18). Furthermore, Lin et al. (19) also reported that certain LAB strains, including L. rhamnosus, L. fermentum, L. acidophilus, L. paracasei, and $L$. plantarum, possess acid tolerance up to $75.8 \%$ at exposure to a pH of 2.0 for $3 \mathrm{~h}$. Lee et al. (20) reported that the acidity of kimchi reached $\mathrm{pH} 3.2$ after 14 days of fermentation. Therefore, it is not surprising that certain dominant strains in mukeunji, present in acidic conditions, can survive in simulated gastric fluid with higher survival rates. It was previously reported that certain strains of $L A B$ isolated from kimchi, including L. casei, L. acidophilus, L. sakei, L. plantarum, and Le. mesenteroides, exhibit resistance to $0.5 \%$ ox-gall (18). Therefore, the $L A B$ isolated in this study were exposed to ox-gall, and certain strains exhibited higher tolerance as shown in Table 1. Previously, the bile tolerance of prebiotic $L A B$ was reported to range from 23.5$72.4 \%$ (19), suggesting that the strains displaying survival in the current study may possess prebiotic properties.

Macrophage activation by LAB isolated from mukeunji In order to evaluate macrophage activation by the isolated $L A B$ strains, the murine macrophage cell line RAW264.7 was co-cultured with each LAB for $24 \mathrm{~h}$. Cell viability, as determined by trypan blue exclusion and MTT assays, was not affected by strains of LAB, indicating that the selected $L A B$ strains did not cause host damage (data not shown). Production of the inflammatory cytokines TNF- $\alpha$ and IL- 6 by RAW264.7 cells was then quantified in the culture supernatant using commercial ELISA kits. Among the LAB strains isolated from mukeunji, $\mathrm{K} 17(150.07 \pm 8.21 \mathrm{pg} / \mathrm{mL}), \mathrm{M} 2-10$ (131.31 $\pm 4.22 \mathrm{pg} / \mathrm{mL}), \mathrm{M} 2-3$ (122.29 \pm $0.01 \mathrm{pg} / \mathrm{mL}), \mathrm{M} 2-2(112.58 \pm 5.42 \mathrm{pg} / \mathrm{mL})$, and D7 (93.84 $\pm 1.84 \mathrm{pg} /$ $\mathrm{mL}$ ) exhibited strong immune-boosting effectscompared to $1 \mu \mathrm{g} \mathrm{LPS}$
Table 1. Acid and bile tolerance of selected LAB isolates

\begin{tabular}{cccc}
\hline \multirow{2}{*}{ Strains } & \multicolumn{2}{c}{ Colony number $(\log$ CFU/mL) } & $\begin{array}{c}\text { Bile tolerance }{ }^{2)} \\
(\%)\end{array}$ \\
\cline { 2 - 3 } & $\mathrm{pH} 7.0$ & $\mathrm{pH} 2.0$ & 77.1 \\
D7 & $9.19 \pm 0.12$ & $5.95 \pm 0.05$ & 63.5 \\
K2 & $9.58 \pm 0.12$ & $4.37 \pm 0.11$ & 72.7 \\
K17 & $9.58 \pm 0.13$ & $4.32 \pm 0.23$ & 63.5 \\
L2 & $9.07 \pm 0.70$ & $3.70 \pm 0.07$ & 85.0 \\
M2-2 & $8.71 \pm 0.06$ & $3.56 \pm 0.14$ & 66.6 \\
M2-3 & $9.04 \pm 0.31$ & $4.65 \pm 0.53$ & 75.0 \\
M2-10 & $9.17 \pm 0.45$ & $4.32 \pm 0.76$ & 83.3 \\
M3-2 & $9.34 \pm 0.12$ & $4.17 \pm 0.23$ & 67.5 \\
M3-7 & $9.39 \pm 0.42$ & $3.30 \pm 0.41$ & 53.4 \\
O8 & $9.20 \pm 0.52$ & $3.06 \pm 0.34$ & 65.1 \\
W22 & $9.44 \pm 0.11$ & $4.08 \pm 0.04$ & 55.6 \\
\hline
\end{tabular}

${ }^{1)}$ Each value in the table represents the mean value \pm standard deviation (SD) from three trials.

${ }^{2)}$ Bile tolerance $(100 \%)=($ Increment of OD in MRS with ox-gall/increment of OD in MRS broth without ox-gall)x100.

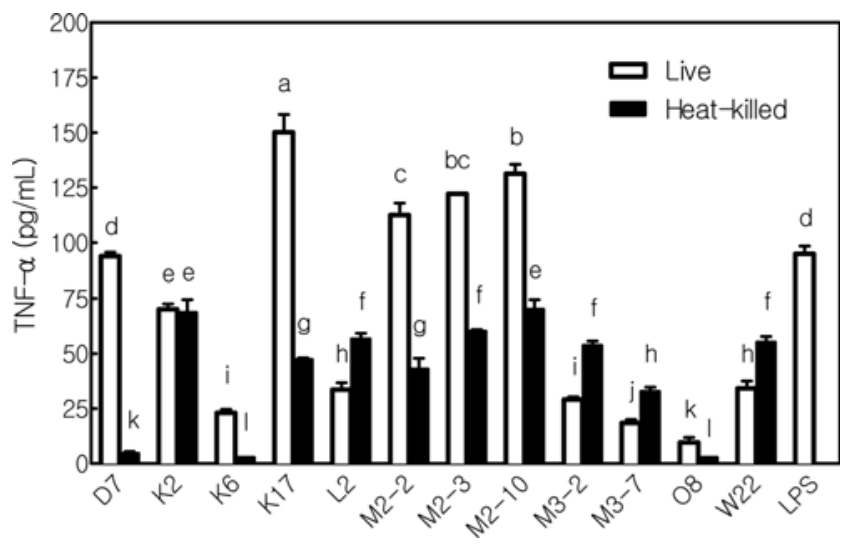

Fig. 1. TNF- $\alpha$ production by RAW264.7 cells after stimulation by LAB strains isolated from mukeunji (means \pm SEM). Bars sharing the same letter are not significantly different $(p<0.05)$.

(88.96 $\pm 5.26 \mathrm{pg} / \mathrm{mL})$, used as the positive control (Fig. 1, blank bars). Strains including K2 $(68.66 \pm 5.77 \mathrm{pg} / \mathrm{mL}), \mathrm{K} 17(47.38 \pm 0.72 \mathrm{pg} / \mathrm{mL}), \mathrm{L} 2$ $(56.66 \pm 2.56 \mathrm{pg} / \mathrm{mL}), W 22(53.82 \pm 1.89 \mathrm{pg} / \mathrm{mL}), \mathrm{M} 2-2(43.02 \pm 4.76$ $\mathrm{pg} / \mathrm{mL}), \mathrm{M} 2-3(60.21 \pm 0.71 \mathrm{pg} / \mathrm{mL}), \mathrm{M} 2-10(70.08 \pm 4.39 \mathrm{pg} / \mathrm{mL}), \mathrm{M} 3-2$ $(55.24 \pm 2.47 \mathrm{pg} / \mathrm{mL})$, and $\mathrm{M} 3-7(29.12 \pm 1.29 \mathrm{pg} / \mathrm{mL})$ exhibited potent ability to stimulate RAW264.7 cells even when heat-killed, as determined by TNF- $\alpha$ production (Fig. 1, filled bars).

IL-6 production by RAW264.7 cells in response to mukeunjiisolated $L A B$ was also determined, as shown in Fig. 2. Specifically, M2-2 (126.34 $\pm 19.78 \mathrm{pg} / \mathrm{mL}), \mathrm{K} 17$ (114.57 $\pm 22.21 \mathrm{pg} / \mathrm{mL}), \mathrm{M} 2-3$ (105.28 \pm $8.62 \mathrm{pg} / \mathrm{mL}), \mathrm{D} 7(82.79 \pm 28.62 \mathrm{pg} / \mathrm{mL})$, and $\mathrm{M} 2-10$ (76.17 $\pm 12.56 \mathrm{pg} /$ $\mathrm{mL}$ ) exhibited increased secretion of IL- 6 compared to $1 \mu \mathrm{g}$ LPS $(16.92 \pm 0.95 \mathrm{pg} / \mathrm{mL}$ ) (Fig. 2, blank bars). In the assessment of IL-6 production upon treatment with heat-killed $L A B$, only $M 3-2$ $(33.00 \pm 4.40 \mathrm{pg} / \mathrm{mL}), \mathrm{W} 22(22.13 \pm 2.80 \mathrm{pg} / \mathrm{mL})$, and M2-3 $(15.06 \pm$ $2.12 \mathrm{pg} / \mathrm{mL}$ ) were determined to exert augmented activation of RAW264.7 cells compared to $1 \mu \mathrm{g}$ LPS (Fig. 2, filled bars). 


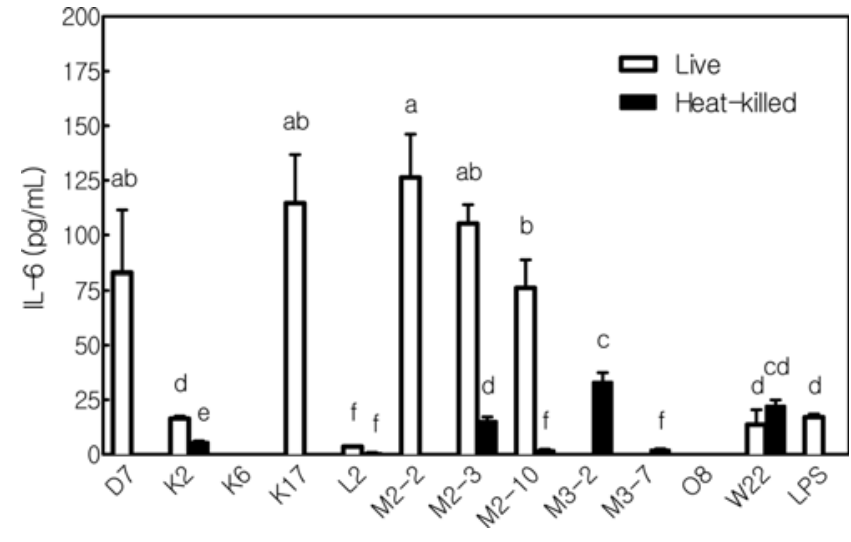

Fig. 2. IL-6 production by RAW 264.7 cells after stimulation by LAB strains isolated from mukeunji (means \pm SEM). Bars sharing the same letter are not significantly different $(p<0.05)$.

Inflammation involves a complex reaction of immune cells for effective removal of exogenous materials. Moreover, various cytokines are involved in the macrophage-initiated innate immune response. Following analysis of TNF- $\alpha$ and IL- 6 production, it was clear that certain LAB strains, such as K17, D7, M2-2, M203, and M2-10, sufficiently boosted macrophage activity, resulting in the production and secretion of inflammatory cytokines (Fig. 1 and 2).

Even though the majority of bacteria are killed in the digestive tract, their cellular components remain in the digestive tract where they may aid in boosting of the immune system by activation of receptors for pathogen-associated molecular patterns, including tolllike receptors. Therefore, heat-killed bacteria were also tested in this study by adding $L A B$ pre-treated at $100^{\circ} \mathrm{C}$ for $30 \mathrm{~min}$ to the RAW264.7 cell culture, after which TNF- $\alpha$ was quantified. Strains $L 2$, W22, and M3-2 exerted increased TNF- $\alpha$ production even after heat treatment (Fig. 1). Similarly, the immune-boosting effects, as determined by IL- 6 secretion, were detected after heat treatment only in the M32-treated group. Thus, intracellular microbial products exposed to extracellular fluid by cell rupture may activate macrophages in the digestive tract (Fig. 2). Furthermore, strain L2, which displayed higher survival in both acid and bile, demonstrated lower activation of murine macrophages under live conditions. These data may indicate
Table 2. Identification of LAB strains through $16 \mathrm{~S}$ rRNA gene sequence analysis

\begin{tabular}{cll}
\hline $\begin{array}{c}\text { Number of } \\
\text { strain }\end{array}$ & \multicolumn{1}{c}{$\begin{array}{c}\text { LAB isolate identified } \\
\text { (NCBI accession number) }\end{array}$} & Similarity (\%) \\
\hline D7 & Lactobacillus plantarum (CP005942.2) & 100 \\
K2 & Weissella cibaria (KJ095644.1) & 100 \\
K6 & Weissella cibaria (KM668164.1) & 100 \\
K17 & Lactobacillus sakei (KM267631.1) & 100 \\
L2 & Weissella cibaria (KM668164.1) & 100 \\
M2-2 & Lactobacillus plantarum (CP005942.2) & 100 \\
M2-3 & Lactobacillus plantarum (CP005942.2) & 100 \\
M2-10 & Lactobacillus plantarum (KJ779104.1) & 100 \\
M3-2 & Pediococcus parvulus (HM562983.1) & 100 \\
M3-7 & Pediococcus parvulus (GU116592.1) & 100 \\
O8 & Weissella cibaria (KM668164.1) & 100 \\
W22 & Pediococcus parvulus (GU116592.1) & 100
\end{tabular}

${ }^{1)} 16 \mathrm{~S}$ rRNA gene sequences of LAB strains were compared to the NCBI sequence database.

that the survival of microorganisms in the digestive tract does not directly dictate the activation of macrophages. Various pathogenassociated molecular pattern (PAMP) recognizing receptors are present on the surface of immune cells. Indeed, it was previously determined that intracellular bacterial products, including $\mathrm{CpG}$ islands, are potent activators of toll-like receptors expressed on macrophages as PAMPs (21).

Identification of selected LAB Following the assessment of tolerance under acidic and bile conditions and examination of immune-boosting effects, the selected $L A B$ were identified by complementary approaches of $16 \mathrm{~S}$ rRNA gene sequencing and SDSPAGE of whole-cell proteins. The LAB examined by $16 \mathrm{~S}$ rRNA gene sequencing were identified as L. plantarum, L. sakei, Weissella cibaria, and Pediococcus parvulus, as shown in Table 2. Whole-cell protein patterns of the 12 isolates that represented each identified LAB species are presented in Fig. 3, along with their specific reference strains. Reference strains were chosen according to the results from the $16 \mathrm{~S}$ rRNA gene sequencing (Table 2). The isolates represented in the lanes with even numbers in Fig. 3 showed whole-cell protein

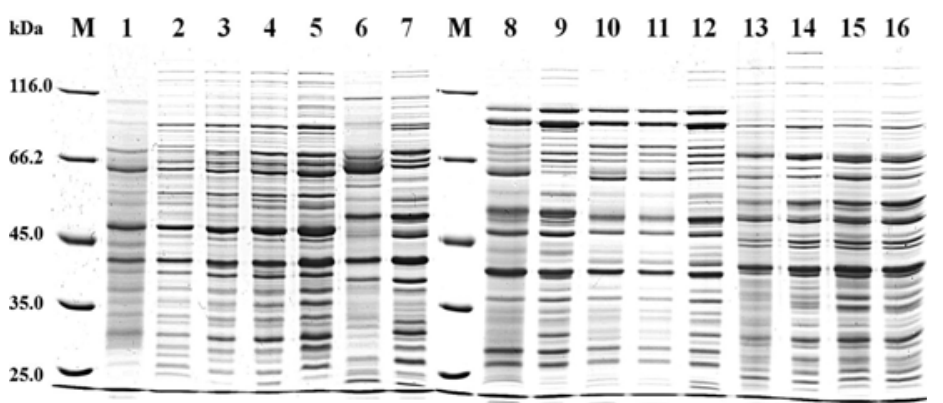

Fig. 3. Whole-cell protein profiles of $12 \mathrm{LAB}$ strains isolated from mukeunji and their reference strains. Lanes: $\mathrm{M}$, protein molecular mass ladder (kDa); 1, L. plantarum ATCC 10241; 2, D7; 3, M2-2; 4, M2-3; 5, M2-10; 6, L. sakei KCTC 3598; 7, K17; 8, W. cibaria KCTC 3746; 9, K2; 10, K6; 11, O8; 12, L2; 13, P. parvulus UCD VEN 253; 14, W22; 15, M3-7; 16, M3-2.

Food Sci. Biotechnol. 
patterns identical to those of the reference strains.

In summary, macrophage activation by addition of specific Lactobacillus species in vitro demonstrated augmented secretion of TNF- $\alpha$ and IL-6. In comparison, Pediococcus and Weissella species showed increased immune activation following heat-treatment, suggesting that certain LAB present in mukeunji may act as immuneboosting agents regardless of their survival in the digestive tract. This immune-boosting effect may be critical to both the young and elderly generations as well as individuals in areas of pandemic microbial/viral outbreaks.

Acknowledgment This study was supported by a grant from the Kyung Hee University in 2012 (KHU-20120341).

Disclosure The authors declare no conflict of interest.

\section{References}

1. Allen A, Leonard AJ, Sellers LA. The mucus barrier. Its role in gastroduodenal mucosal protection. J. Clin. Gastroenterol. 10(Suppl 1): S93-S98 (1988)

2. Yu QH, Yang Q. Diversity of tight junctions (TJs) between gastrointestinal epithelial cells and their function in maintaining the mucosal barrier. Cell Biol. Int. 33: 78-82 (2009)

3. Liddiard K, Rosas M, Davies LC, Jones SA, Taylor PR. Macrophage heterogeneity and acute inflammation. Eur. J. Immunol. 41: 2503-2508 (2011)

4. Martinez-Pomares L, Gordon S. Antigen presentation the macrophage way. Cell 131: 641-643 (2007)

5. Ziegler K, Unanue ER. Identification of a macrophage antigen-processing event required for I-region-restricted antigen presentation to $\mathrm{T}$ lymphocytes. J. Immunol. 179: 5-11 (2007)

6. Jeong $\mathrm{SH}$, Jung JY, Lee $\mathrm{SH}$, Jin HM, Jeon CO. Microbial succession and metabolite changes during fermentation of dongchimi, traditional Korean watery kimchi. Int. J. Food Microbiol. 164: 46-53 (2013)

7. Jeong SH, Lee HJ, Jung JY, Lee SH, Seo HY, Park WS, Jeon CO. Effects of red pepper powder on microbial communities and metabolites during kimchi fermentation. Int. J. Food Microbiol. 160: 252-259 (2013)
8. Hong Y, Li J, Qin P, Lee SY, Kim HY. Predominant lactic acid bacteria in Mukeunji, a long-term-aged kimchi, for different aging periods. Food Sci. Biotechnol. 24: 545-550 (2015)

9. Kim SE, Kim YH, Lee H, Kim DO, Kim HY. Probiotic properties of lactic acid bacteria isolated from Mukeunji, a long-term ripened kimchi. Food Sci. Biotechnol. 21: 1135-1140 (2012)

10. Neumann E, Oliveira MA, Cabral CM, Moura LN, Nicoli JR, Vieira EC, Cara DC, Podoprigora GI, Vieira LQ. Monoassociation with Lactobacillus acidophilus UFV-H2b2O stimulates the immune defense mechanisms of germfree mice. Braz. J. Med. Biol. Res. 31: 1565-1573 (1998)

11. Hernani Mde L, Ferreira PC, Ferreira DM, Miyaji EN, Ho PL, Oliveira ML. Nasal immunization of mice with Lactobacillus casei expressing the pneumococcal surface protein $C$ primes the immune system and decreases pneumococcal nasopharyngeal colonization in mice. FEMS Immunol. Med. Mic. 62: 263-272 (2011)

12. Jung HJ, Hong Y, Yang HS, Chang HC, Kim HY. Distribution of lactic acid bacteria in garlic (Allium sativum) and green onion (Allium fistulosum) using SDS-PAGE whole cell protein pattern comparison and $16 \mathrm{~S}$ rRNA gene sequence analysis. Food Sci. Biotechnol. 21: 1457-1462 (2012)

13. Hong Y, Yang HS, Li J, Han SK, Chang HC, Kim HY. Identification of lactic acid bacteria in salted Chinese cabbage by SDS-PAGE and PCR-DGGE. J. Sci. Food Agr. 94:296-300 (2014)

14. Yoon RG, Kim SJ, Kim HS, Choi CG, Kim JS, Oh J, Chung SJ, Lee CS. The utility of susceptibility-weighted imaging for differentiating Parkinsonism-predominant multiple system atrophy from Parkinson's disease: Correlation with 18Fflurodeoxyglucose positron-emission tomography. Neurosci. Lett. 584: 296301 (2015)

15. National Center for Biotechnology Information. Available from: http:// blast.ncbi.nlm.nih.gov. Accessed Apr. 17, 2013.

16. Lee JY HK, Kim HS, Kim G, Sung SI. Isolation and identification of lactic acid bacteria inhibiting gastro-intestinal pathogenic bacteria of domestic animal.Microbiol. Biotechnol. Lett. 30: 129-134 (2002)

17. Xanthopoulos V, Litopoulou-Tzanetaki E, Tzanetakis N. Characterization of Lactobacillus isolates from infant faeces as dietary adjuncts. Food Microbiol. 17: 205-215 (2000)

18. Chang JH, Shim YY, Cha SK, Chee KM. Probiotic characteristics of lactic acid bacteria isolated from kimchi. J. Appl. Microbiol. 109: 220-230 (2010)

19. Lin WH, Wu CR, Fang TJ, Lee MS, Lin KL, Chen HC, Huang SY, Hseu YC. Adherent properties and macrophage activation ability of 3 strains of lactic acid bacteria. J. Food Sci. 76: M1-M7 (2011)

20. Lee JS, Heo GY, Lee JW, Oh YJ, Park JA, Park YH, Pyun YR, Ahn JS. Analysis of kimchi microflora using denaturing gradient gel electrophoresis. Int. J. Food Microbiol. 102: 143-150 (2005)

21. Nicaise V, Roux M, Zipfel C. Recent advances in PAMP-triggered immunity against bacteria: pattern recognition receptors watch over and raise the alarm. Plant Physiol. 150: 1638-1647 (2009) 